\title{
Design on Management End Software of Network Teaching Platform
}

\author{
Zhe $\mathrm{Li}^{1, \mathrm{a}}$, Hui Ma ${ }^{2, \mathrm{~b}}$ \\ ${ }^{1}$ College of International Exchange, Bohai University, Jinzhou, 121013, China \\ ${ }^{2}$ School of Mathematics and Physics, Bohai University, Jinzhou, 121013, China \\ a503412508@qq.com, bhuima2016@163.com
}

Keywords: network teaching platform; management end; software design; business process; module structure; data access

\begin{abstract}
Network teaching can promote the reform of education concept, teaching content and educational method, improving the quality of teaching and the learners' learning ability and ability of survival and development in the information society. A complete network teaching platform including students, teachers and management end, in this paper, the management end to carry on the design. Design content includes three aspects: first, using the business flow chart for business process design; second is follow the principle of abstraction and information concealment module structure design; another is based on Spring JDBC data access design. In this paper, the research achievements, it can solve the problem of key software development technology, the actual development process to fully mix software to develop new technology, in order to improve the system suitability.
\end{abstract}

\section{Introduction}

Network teaching is a school using computer network as the main means of teaching, is an important form of distance education, is the use of computer equipment and Internet technology implement information-based education teaching model for students. Network teaching can realize long distance, at the same time, real-time, interactive teaching and learning the new teaching mode, is a powerful complement "field scene teaching" model, is the general trend of education informationization and network and goals. Network teaching compared with traditional teaching mode, can cultivate students' information acquisition, processing, analysis, innovation and utilization and communication ability, etc. Network teaching can cultivate students' good information literacy, the information technology as a means of support lifelong learning and cooperative learning, in order to adapt to the information society of the study, work and life lays the necessary foundation.

Network education in the higher education modernization is playing an increasingly important role. Through the network teaching, creating a digital learning environment, to promote the reform of the education concept, teaching content and method, to improve the teaching quality and efficiency of education, to cultivate learners have good social culture and values, to improve learners' learning ability and the ability of survival and development in the information society. In the implementation of the network teaching, support teaching activity teaching platform integrates all kinds of network teaching application subsystem and tools, the technical basis of network teaching. Although both at home and abroad has developed many network teaching platform software, but from the perspective of the function and application effect of the software is still in the exploratory stage.

In the face of scientific and technological progress and the rapid development of social economy, our country's higher education from the aspects such as management system, teaching mode, curriculum reconstruction are facing serious challenges, there are many don't adapt. From the school's point of view, in order to make students master more knowledge, the first thought is designed for students more courses. But as the knowledge explosion era, colleges and universities is generally restricted by limited study time with students total teaching hours. To this end, many schools want to carry out network teaching, and use the network teaching platform to speed up the 
knowledge transfer. Now the application of network teaching platform, is generally the teaching information network, realize the automation of the teaching process, but under the traditional teaching mode and management system, the role of network teaching platform has not fully realized. Repeat construction of specific performance among schools, also course many problems, such as lack of reconstruction and integration.

A complete network teaching platform software including students, teachers and management end, in this paper, the management end to carry on the design, to build perfect network teaching platform to lay a solid foundation.

\section{Business Process Design}

Business process diagram (BPD) is to use some symbols and attachment to represent a particular. It is a kind of description in the business relationship between each unit, personnel system, operation sequence and management information flow chart of business process diagrams can be used to help analyst to find in a business process is not reasonable flow, is a physical model. Business flow chart describes the complete business process, and the center is the business process, the concept of general no data. Business process diagrams used symbols are shown in Fig. 1.

\begin{tabular}{|c|c|c|c|c|c|c|}
\hline Symbol & & & & $\longrightarrow$ & & \\
\hline Name & Entity & $\begin{array}{l}\text { Reports on } \\
\text { input/output }\end{array}$ & Handling & $\begin{array}{l}\text { Business } \\
\text { flow }\end{array}$ & Document & Store \\
\hline
\end{tabular}

Fig. 1. Symbol of business process diagram

Network teaching platform management software business process is shown in Fig. 2.

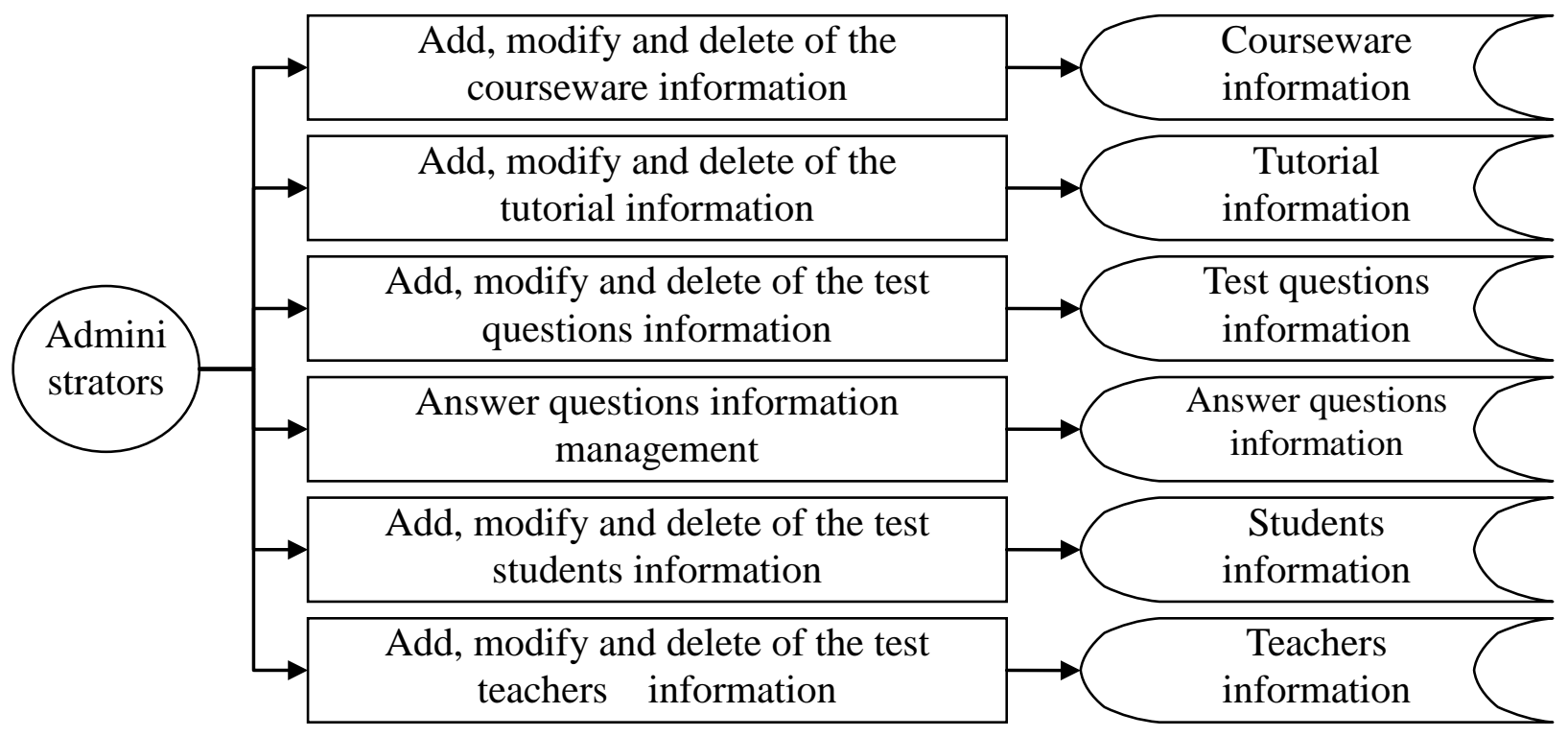

Fig. 2. Business process on administrator client software

\section{Module Structure Design}

Module is data executable statement such as a collection of objects, programs. are individually named and can be accessed by name. Modularization is to divide the program into several modules, each module to complete the function of a child, the module together to form a whole, can meet the target function. Modular structure design should follow the principle of abstraction and information concealment, etc.

Abstraction is the human in the process of know the world and describe the world commonly used method of thinking. People realize in practice, some things in the real world, states, or between 
processes, there are always some similar aspects. Abstraction is the concentration and sum up the similar aspects, ignored the differences between them. Modular design of the software can have different level of abstraction. At the highest levels of abstraction, you can use the problems of environment language description method. While on the lower level of abstraction it uses procedural methods. The abstract methods commonly used in the process of software, such as process abstraction, data abstraction, and control the abstract 3 kinds.

Information hiding is refers to the implementation details of each module is hidden to other modules. That is to say, the information contained in a module, don't allow other module USES don't need these information. Usually, effective modularity can be realized by defining a set of independent modules, these modules communication between each other just use for implementing software function is the necessary information.

Through abstraction, we can determine the process of component software entities, and through hidden information, you can define and implement process of the module details and access restrictions of local data structure. Adopts the principle of information hiding design software for testing and maintenance during the period of software modification work provides great convenience. Because most of the data and process for the rest of the software is hidden, so when it was introduced some of the unrealized errors are rarely able to spread to other parts of the software.

The module structure design of the Network teaching platform end software as shown in Fig. 3.

\begin{tabular}{|c|c|}
\hline \multicolumn{2}{|c|}{ Management End Software of Network Teaching Platform } \\
\hline Courseware information management & Tutorial information management \\
\hline Courseware information add & Tutorial information add \\
\hline Courseware information modify & Tutorial information modify \\
\hline Courseware information delete & Tutorial information delete \\
\hline Courseware information query & Tutorial information query \\
\hline Courseware information download & Tutorial information download \\
\hline Test questions information management & Answer questions information management \\
\hline Test questions information Add & Answer questions information query \\
\hline Test questions information modify & Answer questions information audit \\
\hline Test questions information delete & Answer questions information delete \\
\hline Test questions information query & Answer questions information upload \\
\hline Test questions information download & Answer questions information download \\
\hline Students information management & Teachers information management \\
\hline Students information add & Teachers information add \\
\hline Students information modify & Teachers information modify \\
\hline Students information delete & Teachers information delete \\
\hline Students information query & Teachers information query \\
\hline Students user authorization & Teachers user authorization \\
\hline
\end{tabular}

Fig. 3. Modular structure on management end software of network teaching platform 


\section{Data Access Design}

Data access is a basic work in software development. JDBC (Java Data Base Connectivity) is a Java API for executing SQL statements can be for a variety of relational database generation Data access method. Spring is an open source framework, the core technology is a lightweight container, based on the J2EE enterprise application development, it provides the omni-directional supports application framework. Spring JDBC is the Spring framework of JDBC encapsulation, USES the template design pattern. Perform various operations on database, the original needed to use JDBC directly through repetitive code template to complete, simplifies the use of JDBC, improve the efficiency of software development, software easier to maintain and extend.

Spring JDBC abstract framework provided by the core package, data source package, object, support package, etc. Complete data access, main points of three steps.

Step 1: entity class structure. Entity class is commonly known as POJO, mainly as a data management and business logic processing level category, this class is not implemented within the framework of the special interface, just as a data container used to store data persistence.

Step 2: write the DAO implementation. Spring JDBC DAO inherits from Spring to provide JdbcDaoSupport classes. Spring for the benefits of the writing of the DAO, refine the data access exception, enrich the exception type; Use templates callback mode, developers write code, to simplify programming.

Step 3: configure the transaction manager. Transaction management plays an important role in the application, it is a component unit of work, of a series of tasks in this unit of work, all tasks must be performed at the same time. Only two possible results, all the task execution is successful, or failed to perform all the tasks. Configuration transaction manager including configuration data source, configuration, transaction management objects, the configuration transaction strategy, configuration of AOP, etc.

\section{Conclusion}

As teaching demand, teaching theory and technology, the continuous development of information and communication technology, network teaching platform, there have been some new trends and hot: from a single network teaching platform to support the development of multi-mode network teaching support environment, combined with resource center, from general form to personalized support for course or the teacher's teaching, and digital campus it system integration, based on the content of the packing standard of courseware and learning management, pay attention to the application of new technologies and social software, pay attention to knowledge management, using the component technology in the development of supporting environment. Actual software development process, in this paper, based on the design, combined with these new trends, in order to improve the adaptability of the network teaching platform.

\section{References}

[1] X. J. Du, "The design and implementation of computer network teaching management system," Journal of Chifeng University (Natural Science Edition), vol. 28, no. 4, pp. 43-45, 2012.

[2] X. X. Guo, "The design and implementation of network teaching platform based on Web," Master's degree of Jilin University, 2016.

[3] H. X. Wang, "Research on the design and development of teaching management information system," Journal of Suihua University, vol. 34, no. 12, pp. 123-124, 2014.

[4] L. Yao, "Design and implementation of network teaching platform in universities," Practical Electronics, vol. 23, no. 4, pp. 74, 2016. 
[5] J. Du, L. J. He, H. J. Ouyang, "Design and Implementation of Online Examination System Based on JDBC and DAO Mode," Journal of Xianyang Normal University, vol. 29, no. 2, pp. 26-29, 2014.

[6] L. Zhang, W. X. Zhang, "Application of Vegetables Transportation and Sales Integrated Management System in Date Persistent Based on Spring and JDBC," Journal of Anhui Agricultural Sciences, vol. 40, no. 7, pp. 4401-4403, 2012.

[7] W. Y. Zhang, M. J. Xu, Y. Xue, "Introduction to Spring Zero Configuration and XML Configuration," Computer Systems \& Applications, vol. 24, no. 2, pp. 270-275, 2015.

[8] J. H. Xu, B. Song, R. Ding, "Research of Spring MVC + Hibernate + jQeury Development Framework Application," Techniques of Automation and Applications, vol. 34, no. 3, pp. 42-46, 2015. 